cup is tilted somewhat and 2 very light film discs with a spoke-like pattern press gently against the ball to keept it in position. The discs are glued to fine steel axes with tipped ends and supported by tip bearings normally used in alarm clocks. The 2 discs touch the ball in its equatorial plane at $90^{\circ}$ to each other, as shown in figure 1. Each spoke pattern interrupts 2 light barriers. The interruptions are counted in order to measure the magnitude and direction of rotation of the discs and hence of the ball. The contents of the counters are read at programmable time intervals by a computer. In this way $x$ - and $y$-coordinates of the animal's path can be recorded. The moment of inertia of the discs increases the effective mass of the ball the animal has to accelerate. The discs also restrict the ball to rotations around axes in the plane of the equator. A 3rd light spokepattern-disc, centred and fixed on top of the needle by a small drop of wax in combination with an additional lightbarrier system allows for the recording of the angular position of the animal (figure 1).

The apparatus has been tested with 2 species of Cicindela and several other beetles. The tracks even of very fast running Cicindelae could be recorded successfully. The animals performed long runs (2-3 h). In most cases they did not show any obvious differences in their behaviour from that observed in the terrarium, provided that a very short nylon thread was inserted as an elastic joint between the needle and the prothorax, which allowed the animal to tilt and roll its prothorax to some extent. Figure 2 shows an $80-$ sec interval of a 30-min recording of a track of Cicindela silvatica. In the experiment the animal orientated towards a single vertical white stripe, $10^{\circ}$ wide in azimuth on a black background. The track with its sudden starts and stops and a running speed up to $25 \mathrm{~cm} / \mathrm{sec}$ could be recorded without difficulty (see figure $2, \mathrm{c}$ ).

1 K.G. Götz and Ch. Gambke, Zum Bewegungssehen des Mehlkäfers Tenebrio molitor. Kybernetik 4, 225 (1968).

2 E. Kramer, The orientation of walking honeybees in odour fields with small concentration gradients. Physiol. Ent. 1, 27 (1976).

3 D. Varjú, Stationary and dynamic responses during visual edge fixation by walking insects. Nature 225,330 (1975).

4 W. B. Kerfoot, Orientometer for study of insect behaviour. Science 162, 477 (1968).

5 E. Buchner, Elementary movement detectors in an insect visual system. Biol. Cybernetics 24, 85 (1976).

\title{
Methods for determining ploidy in amphibians: nucleolar number and erythrocyte size ${ }^{1}$
}

\author{
S. A. George and Michelle R. Lennartz ${ }^{2}$ \\ Biology Department and Neuroscience Program, Amherst College, Amherst (MA 01002, USA), 20 August 1979
}

Summary. Diploid and triploid Xenopus can be easily and reliably distinguished by the size of their erythrocytes. This method has several advantages over other methods, such as counting metaphase chromosomes and counting nucleoli. One problem with the latter method is the reduction in cells with a full complement of nucleoli when regenerating tissue is used.

Triploid amphibians have been produced in the laboratory for a variety of purposes: e.g., to study nucleo-cytoplasmic interactions ${ }^{3}$, to provide histologically identifiable tissue for embryonic transplants ${ }^{4}$, and to investigate effects of cell size and number in the nervous system ${ }^{5}$. Since the methods for inducing triploidy (temperature or pressure shock to the early embryo ${ }^{6,7}$ ) are not $100 \%$ effective, resulting in some treated embryos being diploid $(2 \mathrm{~N})$ rather than triploid $(3 \mathrm{~N})$, it is essential to have reliable and efficient techniques for determining ploidy in these animals.

2 methods are commonly used to measure ploidy: counting chromosomes and counting nucleoli. There are disadvantages to both of these methods. Chromosome counts are laborious and, unless cells are grown in culture, somewhat imprecise because metaphase chromosomes in tissue such as the larval tail tend to be tangled and hard to count Regarding nucleolar counts, it is assumed by most workers that the maximum number of nucleoli per nucleus in tail

Number of nucleoli per nucleus (mean \pm SE) for diploid $(2 \mathrm{~N}$ ) and triploid $(3 \mathrm{~N})$ tail tip cells during ordinary growth (1st squash) and during regeneration (2nd squash)

\begin{tabular}{llll} 
& 1st squash & 2nd squash & t-test \\
\hline $2 \mathrm{~N}$ & $1.53 \pm 0.04$ & $1.47 \pm 0.03$ & $\mathrm{p}=0.23$ \\
$3 \mathrm{~N}$ & $1.80 \pm 0.5$ & $1.57 \pm 0.04$ & $\mathrm{p}<0.0001$ \\
\hline
\end{tabular}

tip epithelial cells is equal to the ploidy of the animal. However, many cell types are known to deviate from this rule $^{8}$, and it is possible to confuse other organelles, such as the Barr body, with nucleoli ${ }^{9}$. Furthermore, caution must be exercised in the choice of tissue to be used in nucleolar counts. Regenerating tail tips are often used for counting chromosomes because regenerating tissue has a higher proportion of metaphase cells with visible chromosomes. It is often convenient to use the already prepared tail squash for counting nucleoli also. However, we have found a reduction in the average number of nucleoli per nucleus in regenerating tail tips compared to normal tail tips from the same animals, as has been reported previously for regenerating mammalian liver ${ }^{10}$.

Analysis of nucleoli. Triploid Xenopus laevis were produced by subjecting fertilized eggs to $400 \mathrm{~b}$ of hydrostatic pressure for $6 \mathrm{~min}$ beginning $5 \mathrm{~min}$ after insemination. Tail tips were removed from $32 \mathrm{~N}$ and 3 previously confirmed $3 \mathrm{~N}$ tadpoles at stage 55 , placed in distilled water and in acetoorcein stain for 5 min each, and squashed on a slide under a coverslip. After 3 days, a 2 nd squash was made from the same animals to provide regenerating tissue. The number of nucleoli per nucleus was counted in a total of 989 cells from these preparations. As can be seen in the table, the mean number of nucleoli was significantly lower in regenerating $3 \mathrm{~N}$ tissue. Another way of looking at these data is to consider the proportions of cells with given numbers of nucleoli, as shown in figure 1 . Note the decrease in the 
proportion of $3 \mathrm{~N}$ cells that have 3 nucleoli based on the 2nd squash. While in normal tissue $18.9 \%$ of cells had 3 nucleoli, in regenerating tissue only $8.9 \%$ had 3 nucleoli, a significant reduction $\left(\chi^{2}\right.$-test, $\left.p=0.0004\right)$. Thus it is preferable not to use regenerating tissue for nucleolar counts, since fewer cells have the maximum number of nucleoli, which is the critical number for determining ploidy.

A new method for measuring ploidy in Xenopus. The rationale for this method is that triploids have larger cells than diploids, so cell size should be a useful indicator of ploidy if a cell type can be found that is easily obtained and identified, and reasonably uniform in size in animals of each ploidy. The erythrocyte turns out to be such a cell. $5-10 \mu 1$ of blood was obtained in a pipette by making a small incision in the skin near the knee of young postmetamorphic animals. A small drop of blood was placed on a slide, immediately coverslipped, and sealed with per-

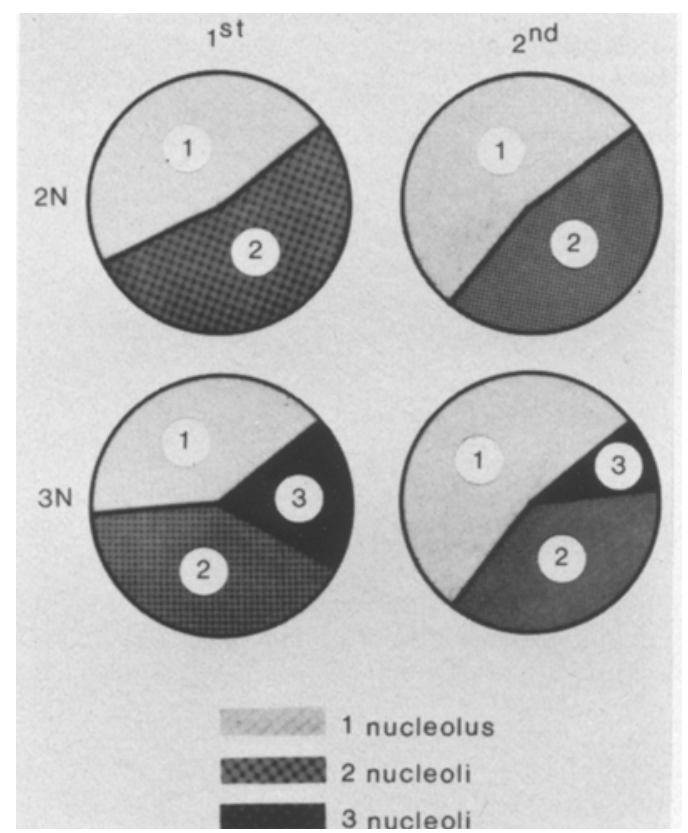

Fig. 1. Proportions of diploid and triploid tail tip cells having 1,2 and 3 nucleoli during ordinary growth (1st) and during regeneration (2nd).

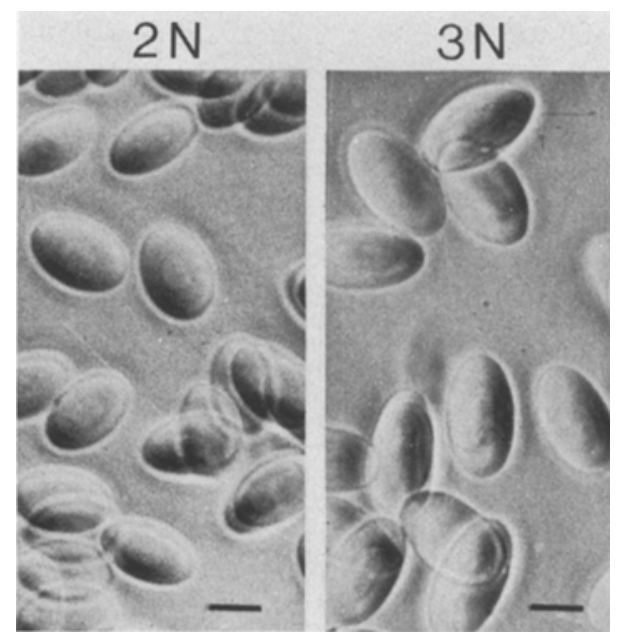

Fig. 2. Diploid and triploid Xenopus erythrocytes. Scale $=10 \mu \mathrm{m}$.

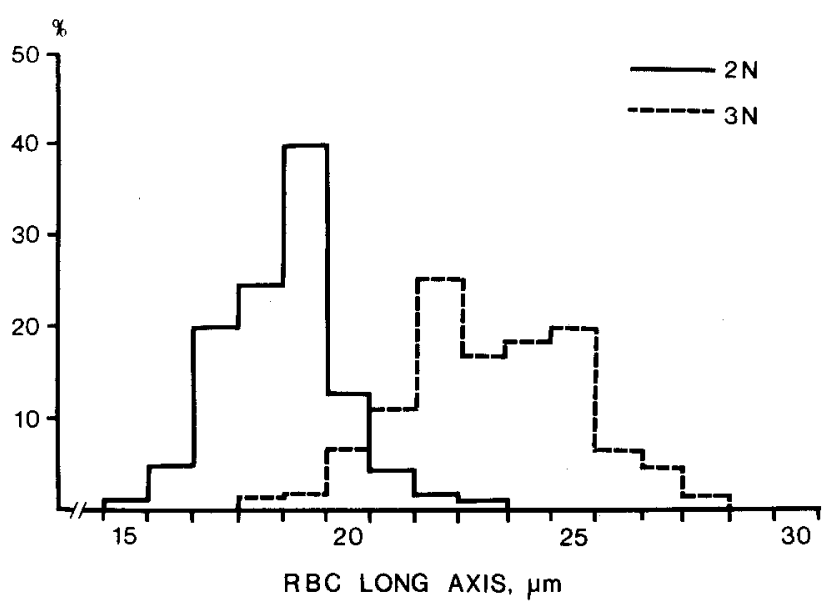

Fig. 3. Distribution of long axis dimensions in diploid and triploid erythrocytes.

mount. It proved important to make the drop just large enough to spread evenly under the coverslip, to prevent either rapid drying of the sample (if the drop was too small) or movement of cells on the slide (if the drop was too large). The outlines of erythrocytes were drawn using a camera lucida, and the largest dimension on the profile of each cell was measured. Erythrocytes constitute the vast majority of cells in these preparations, and the occasional. leucocyte can be recognized by its spherical or irregular shape, as distinct from the smooth, ellipsoidal erythrocytes (figure 2). These smears remained useable for $2 \mathrm{~h}$ or more, after which cell size changed and lysis occurred.

In developing this procedure, long axes of 1058 cells from 4 untreated diploids and 4 previously confirmed triploids were measured. The distribution of long axis lengths for each ploidy is shown in figure 3 . The diploid mean length was $18.48 \mu \mathrm{m}$ (SD $1.19 \mu \mathrm{m}$ ); the triploid mean was $23.22 \mu \mathrm{m}$ (SD $1.83 \mu \mathrm{m})$. The difference in means between cells of the 2 ploidies was highly significant (t-test, $\mathrm{p}<0.0001$ ), but the difference in means among animals within each ploidy was not conventionally significant. How many cells should be measured to provide a reliable indication of ploidy? Accepting the standard deviations given above, and assuming that long axis length is normally distributed, then if the mean long axis length of any 6 randomly selected erythrocytes is less than $20.35 \mu \mathrm{m}$, the probability that the animal is diploid is more than 0.9999 ; if the mean is greater than $20.35 \mu \mathrm{m}$, the probability is more than 0.9999 that the animal is triploid.

The advantage of this method is that it is simple and rapid (requiring no staining procedures and only a few min to draw and measure the necessary number of cells); it is also reliable, minimally invasive, and applicable to postmetamorphic animals as well as larvae.

1 Research supported by NIH grant EY 01662.

2 Present address of M.R.L.: Dept. of Biochemistry, University of Michigan, Ann Arbor, MI 48104, USA.

3 G. Fankhauser, Int. Rev. Cytol. I, 165 (1952).

4 E.P. Volpe and J. B. Turpen, Science 190, 1011 (1975).

5 S. A. George, Invest. Ophthal. 17, 237 (1978).

6 S. Dasgupta, J. exp. Zool. 151, 105 (1962).

7 R. Tompkins, J. exp. Zool. 203, 251 (1978).

8 H. Busch and K. Smetana, The Nucleolus. Academic Press, New York 1970

9 G.B. Petersen and A.J. Therkelson, Exp. Cell Res. 28, 590 (1962).

10 S. Mironescu and C. Dragomir, Cancer Res. 27, 1819 (1967). 